\title{
Altered MiRNA Expression in Gastric Cancer: a Systematic Review and Meta-Analysis
}

\author{
Qi-Xian Wang You-Qing Zhu Hu Zhang Jun Xiao \\ Department of Gastroenterology and Laboratory of Gastroenterology, Zhongnan Hospital, Wuhan \\ University, Wuhan, Hubei, China
}

\section{Key Words}

Gastric cancer $•$ MiRNA $•$ Microarray $•$ Biomarker $•$ Diagnosis

\begin{abstract}
Background/Aims: Aberrant microRNA expression has the potential to be used for early diagnosis of gastric cancer or to predict survival and treatment response. This study performed a systematic review and meta-analysis of altered miRNAs in gastric cancer in order to assess the use of miRNAs as novel biomarkers for early detection and prognosis prediction of gastric cancer. Methods: We retrieved published articles from the PubMed online database and obtained different sets of data on miRNAs expression profiling in gastric cancer and highlighted the most frequently dysregulated miRNAs in gastric cancer. We then extracted studies that used quantitative RT-PCR and then pooled them together by using meta-disc software (version 1.4). Results: We found that there were 47 aberrantly expressed miRNAs in gastric cancer (29 up-regulated and 18 down-regulated) that were most frequently reported in the literature. In publications that provided information on specific miRNA expression vs. diagnostic value, the pooled data showed good sensitivity and specificity as well as high levels of overall accuracy. However, specimen types could be a factor that introduces substantial heterogeneity. Published studies also showed association of altered miRNA expression with clinicopathological data from gastric cancer patients. Conclusion: Thus, various miRNAs are differentially expressed in gastric cancer and some of them could be further evaluated as biomarkers for early diagnosis of gastric cancer and prediction of prognosis or treatment response.
\end{abstract}

Jun Xiao and You-Qing Zhu,

KARGER 125
Department of Gastroenterology and Laboratory of Gastroenterology, Zhongnan Hospital, Wuhan University, 169 Donghu Road, Wuhan 430071, Hubei, (China)

Tel. +86-18971352366, E-Mail xiaojunzhongnan@163.com, E-Mail uqing_zhu@sina.com 


\section{Introduction}

Gastric cancer is the fourth most common cancer in the world, with an estimated 989,600 new cases and 738,000 deaths globally in 2008 [1]. Approximately $72 \%$ of gastric cancer occurs in developing countries and geographically, the highest incidence rate is in Asia (e.g. Korea, Japan, and China) and parts of South America, whereas the lowest rate is in North America [1]. The overall 5-year survival rate of patients with early stage gastric cancer can be above $90 \%[2,3]$. However, approximately two thirds of gastric cancer patients show tumor metastasis or local invasion at diagnosis. Surgery is the treatment of choice for early stages of the disease. However, the median survival time is only 6 to 9 months for later stage of disease after surgical treatment $[4,5]$. Thus, early detection of gastric cancer is the key to prolong survival of patients and therefore health-care policy for gastric cancer should o be focused on early detection and as well as novel treatment strategies. To date, the commonly used diagnostic tools for detection of gastric cancer are endoscopy, CT, MRI, and EUS and tumor markers (CA199, CEA, and CA724). However, these tools are valuable only in diagnosing late stage cancers [6]. Thus, identification and evaluation of novel molecular markers could therefore improve diagnosis and management of gastric cancer. For this reason, we sought to explore the application of microRNAs as a potential diagnostic and prognostic marker for human patients with gastric cancers.

MicroRNAs (miRNA) are endogenous, small, single-stranded non-coding RNAs that regulate gene expression via either translational repression or mRNA degradation [7, 8]. miRNAs are estimated to regulate up to $30 \%$ of genes in the human genome [9]. Over the past few years, studies of miRNA revealed that miRNA participate in regulation of various biological processes, such as cell proliferation, apoptosis, and differentiation, as well as tumor development, metastasis, angiogenesis, and immune reaction; thus, miRNA play important roles in homeostasis and tumorigenesis $[10,11]$. In this study, we have reviewed the most recent literature on miRNA and performed a meta analysis for potential diagnostic and prognostic value for miRNA in gastric cancer s. On the basis of recent data, we divided our studies into three parts, i.e., the data on miRNA chip analysis, qRT-PCR, and the relationship to clinicopathological factors.

\section{Materials and Methods}

\section{Search strategy}

We thoroughly searched PubMed, Web of Science, and EMBASE online databases for the relevant human studies of miRNAs published in English language up to March of 2014. The following keywords and phrases were used: (stomach neoplasms OR (stomach AND neoplasms) OR (gastric AND "cancer) OR (gastric cancer) OR GC) AND (microRNA OR miRNA). We also reviewed the references cited in these retrieved studies to identify additional studies. Two investigators (Wang and Xiao) independently reviewed the titles, abstracts, and full texts of manuscripts to identify eligible studies. Another investigator (Zhang) joined in data extraction together with the two former investigators. Any disagreements were resolved by a third investigator (Zhu). The data were then extracted from the selected studies and input into tables that contain different characteristics of interest.

\section{Inclusion and exclusion criteria}

The inclusion and exclusion criteria of this meta-analysis were as follows: i). Studies on miRNA in tissue or blood in gastric cancer patients using miRNA microarray and reported on dysregulated miRNAs were included; ii). For studies on miRNA in tissue or specimens including serum, plasma, and peripheral blood using qRT-PCR, if diagnosis value such as sensitivity and specificity were available and (or) data on dysregulated miRNA was available, the article was included; iii). If the sample size in both experimental and control groups was larger than 10 in clinic validation using qRT-PCR, then the study was included; and iv). Only original research papers that were full-text available and published in English were included; otherwise, they were excluded.

\section{KARGER}




\section{Data extraction}

We extracted the data from each included study according to the types of study, i.e., i). In miRNA microarray studies, we extracted data including platform of miRNA microarray chip, specimen type, sample size, the cut-off value for up- and down-regulated miRNA expression, and the list of dysregulated miRNAs; ii). In the validation studies using miRNAs as biomarkers for tumor diagnosis by method of qRTPCR, we focused on the sensitivity and specificity of the dysregulated miRNA, and additional information including specimen type, sample size, the cutoff value, control gene for normalization, AUC (the area under the Receiver operating characteristic curves (ROC) curve) and so on were collected; iii). The previously screened miRNAs were associated with clinicopathological data, e.g., gender, age, tumor size, location, cell proliferation, and TMN stage, lymphatic metastases, pathological type, the target gene of miRNA, prediction of response to radiotherapy and chemotherapy and prognosis of gastric cancer patients.

\section{Statistical analysis}

The analytical software meta-disc version 1.4 (version 1.4; Ramony Cajal Hospital, Madrid, Spain) was used to analyze the diagnostic value and to calculate the 95\% confidence interval. A two-sided p < 0.05 was considered statistically significant. Inconsistency $\left(\mathrm{I}^{2}\right)$ was calculated to test heterogeneity with an $\mathrm{I}^{2}$ value greater than $50 \%$ indicating substantial heterogeneity. Based on the heterogeneity values, we used the random-effect model throughout the statistical tests to compute the data. A regression analysis was performed to explore the possible sources of heterogeneity. A subgroup analysis of the specimen type was performed for sensitivity, specificity, LR+ (positive likelihood ratio), LR- (negative likelihood ratio), and DOR (diagnostic odds ratio). Summary receiver operating characteristic (sROC) curve and the area under the curve (AUC) were also calculated to predict sensitivity and specificity. Other data on miRNA chip and associated clinicopathological data in the validation studies that were not appropriate to be pooled are listed in tables.

\section{Results}

Data on altered miRNA expression using miRNA microarray analysis

In this part of data, we aim to summarize data generated from miRNA microarray analysis on differentially expressed miRNA in gastric cancer in order to highlight the value of using the most commonly altered miRNAs as potential biomarkers in diagnosis of gastric cancer. We found 19 studies reporting altered miRNA expression using various high-throughput miRNA chips as shown in Table 1.

In terms of samples, plasma from gastric cancer and healthy people was used in two studies $[10,11]$, plasma from pre- and post-operative gastric cancer patients were used in one study [21], whereas all other studies utilized tissues from tumors and adjacent normal or real normal mucosa, except for formalin-fixed paraffin-embedded tissue being used in one study [25]. The sample numbers within each study range from 3 pairs to 353 individuals. Except for one study [24] that used qRT-PCR and could only detect a total of 72 miRNAs, all other studies used miRNAs chips and detected at least 326 miRNAs. Three studies [10, 12 ,27] did not provide data on miRNA fold changes while in all other studies, a 1.5 fold change was used to pick up-regulated or down-regulated miRNAs. Histopathological grading information was provided in seven $[12,13,16,18,19,24,26]$ studies.

Analysis of data from the 19 included studies that used miRNA microarray chips revealed a number of miRNAs with altered expression. Although we found hundreds of altered miRNAs, only members from the miR-17-92 cluster and its two paralogues were consistently upregulated [12-19, 22, 23, 25-27]. We have also summarized miRNAs that were up-regulated in at least 4 of the 19 studies and down-regulated in at least 3 studies in Table 2. Specifically, a total of 25 miRNAs, including miR-21 and miR-23a, were most frequently up-regulated and 14 miRNA (including miR-29c and miR-30a-5p) were down-regulated.

Validation of some dysregulated miRNAs in clinical samples

We collected all studies that evaluated the diagnostic value of miRNAs as a novel biomarker in gastric cancer patients. The flowchart explaining our search procedure can be KARGER 
Table 1. Studies of miRNA microarray profiling in fresh gastric cancer tissue samples. NA, not available; GC, gastric cancer

\begin{tabular}{|c|c|c|c|c|}
\hline studies & platform of miRNA microarray & $\begin{array}{l}\text { miRNA } \\
\text { probes }\end{array}$ & $\begin{array}{l}\text { Samples from cancer/ } \\
\text { normal tissue ( } \mathrm{N} \text { or } \\
\text { pairs) }\end{array}$ & $\begin{array}{l}\text { Cutoff } \\
\text { (fold) }\end{array}$ \\
\hline Tchernitsa [12] & $\begin{array}{l}\text { NCode Multi-Species miRNA Microarray Probe Set } \\
\text { V (Invitrogen, CA, USA) }\end{array}$ & 857 & $\begin{array}{l}6 \text { pairs ( } 3 \text { with } / 3 \text { without } \\
\text { lymph node metastases), } \\
\text { intestinal-type }\end{array}$ & median \\
\hline Chen $[13]$ & $\begin{array}{l}2 \text { methods : miRCURY LNA microRNA Array, } \\
\text { v. } 11.0 \text { (Exiqon Life Science,Woburn, Mass)) and } \\
\text { Agilent Human MicroRNA Microarray V2 (Agilent } \\
\text { Technology, Santa Clara, Calif) }\end{array}$ & $\begin{array}{l}1205 \\
723\end{array}$ & $\begin{array}{l}6 \text { (3 advanced gastric } \\
\text { adenocarcinomas) } / 3\end{array}$ & 2 \\
\hline Chen [14] & miRCURY LNA microRNA Array, v.11.0 (Exiqon) & NA & 5 pairs & 3 \\
\hline Yao [15] & Mercury LNA Array ,v. 11.0 + qRT-PCR & 847 & 3 pairs & $2 / 1.5$ \\
\hline Li [16] & $\begin{array}{l}\text { miRCURY LNA Array microRNA chip (Exiqon) } \\
\text { v.14.0 }\end{array}$ & 904 & $\begin{array}{l}6 \text { pairs, intestinal-type } \\
\text { GC }\end{array}$ & 2 \\
\hline Wang [17] & $\begin{array}{l}\text { miRCURY LNA Arrays Exiqon, Vedbaek, } \\
\text { Denmark) v. } 16.0\end{array}$ & NA & 17 pairs & 2 \\
\hline Liu [11] & $\begin{array}{l}\text { Human microRNA microarrays (Agilent } \\
\text { Technologies, Santa Clara, CA) }\end{array}$ & 851 & $\begin{array}{l}7 / 10 \text { age-matched } \\
\text { healthy individuals, } \\
\text { serum samples }\end{array}$ & 2 \\
\hline Zhang [18] & $\begin{array}{l}\text { miRNA chip ,V12.0 (Agilent Technologies, Foster } \\
\text { City, CA) }\end{array}$ & 885 & $\begin{array}{l}3 \text { pairs, distal gastric } \\
\text { adenocarcinoma }\end{array}$ & 1.5 \\
\hline Tsukamoto [19] & $\begin{array}{l}\text { miRNA microarray (Agilent Technologies, Santa } \\
\text { Clara, CA, USA) }\end{array}$ & 470 & $\begin{array}{l}14 \text { (intestinal type) and } \\
8 \text { (diffuse type)/ } 5\end{array}$ & 2 \\
\hline Su [20] & $\begin{array}{l}\text { AFFX miRNA expression chips (Affymetrix, CA, } \\
\text { USA) }\end{array}$ & NA & 16 pairs & 1.5 \\
\hline Konishi [21] & $\begin{array}{l}\text { 3D-Gene miRNA microarray platform (TORAY, } \\
\text { Kamakura, Japan) }\end{array}$ & $\begin{array}{l}\text { NA, } \\
\text { miRBase } \\
15.0\end{array}$ & $\begin{array}{l}3 \text { Pre-operative } \\
\text { plasma/post-operative } \\
\text { plasma }\end{array}$ & 2 \\
\hline Gorur [10] & $\begin{array}{l}\text { The BioMark 96.96 Dynamic Array (Fluidigm, } \\
\text { South San Francisco, CA)+ qRT-PCR }\end{array}$ & 904,704 & $20 / 190$, blood samples & mean \\
\hline Guo [22] & $\begin{array}{l}\text { mParaflo }{ }^{\top M} \text { microfluidic chip (LC Sciences, } \\
\text { Houston, TX, USA) }\end{array}$ & NA & 3 pairs & 1.5 \\
\hline Ding [23] & $\begin{array}{l}\mu \text { Paraflo microfluidic technology (LC Sciences, TX, } \\
\text { USA) }\end{array}$ & $\begin{array}{l}\text { NA, } \\
\text { miRBase } \\
10.0\end{array}$ & 6 pairs & 1.5 \\
\hline Katada [24] & qRT-PCR & 72 & $\begin{array}{l}42 \text { pairs undifferentiated } \\
\text { GC }\end{array}$ & 2 \\
\hline $\mathrm{Li}[25]$ & $\begin{array}{l}\text { The TaqMan Human miRNA Array v1.0 (Early } \\
\text { Access) + qRT-PCR }\end{array}$ & 365 & $\begin{array}{l}30 \text { pairs, formalin-fixed } \\
\text { paraffin-embedded } \\
\text { specimens }\end{array}$ & 2 \\
\hline Ueda [26] & $\begin{array}{l}\text { Ohio State University custom microRNA } \\
\text { microarray chip }\left[\mathrm{OSU}_{-} \mathrm{CCC} \text { v } 3.0\right.\end{array}$ & 326 & $\begin{array}{l}184(103 \text { diffuse-type } \\
\text { and } 81 \text { intestinal-type)/ } \\
169\end{array}$ & 1.5 \\
\hline Carvalho [27] & miRNAChip_human_V2(Portugal) & NA & $\begin{array}{l}37 / 10 \text { (pooled as } 4 \\
\text { samples) }\end{array}$ & NA \\
\hline Deng [28] & NA & NA & 6 pairs & 1.5 \\
\hline
\end{tabular}

Table 2. Expression of the most frequently altered miRNAs in gastric cancer detected by the miRNA microarray

\begin{tabular}{ll}
\hline Up-regulated miRNAs ( $\geq 4$ folds; $n=25$ ) & Down-regulated miRNAs ( $\geq 3$ folds; $n=14)$ \\
\hline miR-17-92 family: miR-17, miR-18a, miR-18b, miR-19a, miR-20a, miR- & miR-29c, miR-30a-5p, miR-30c, miR-30d, miR-31, miR-101, \\
20b, miR-25, miR-92, miR-93, miR-106a, miR-106b. & miR-148a, miR-375, miR-378, miR-451, miR-486-5p, miR- \\
miR-21, miR-23a, miR-23b, miR-27a, miR-34a, miR-103, miR-107, & 638, miR-663, miR-768-3p \\
miR-192, miR-194, miR-214, miR-215, miR-222, miR-223, miR-335 & \\
\hline
\end{tabular}

seen as Figure 1 briefly. A total of 17 studies evaluate 28 panel of miRNAs in total were included. The number of patients in each study ranged between 42 and 391, and the specimens used were plasma, serum, peripheral blood, or gastric juice. The adopted endogenous reference, quantitative method, and the cut-off values were not unified, e.g., for the plasma, U6 was used in three studies [27, 29-32], while Cel-miR-39 used in one study [33]. As for the feasibility to obtain blood sample, almost all studies recruited healthy individual as a normal control except Zhang et al [34] who recruited normal mucosa or minimal gastritis in 99 patients as a control. In addition, Li et al [30] focused on early stages of gastric cancer and Zhang et al [18] focused on serum in distal gastric adenocarcinomas compared with 20 age-matched healthy individuals. 
Fig. 1. Flowchart demonstrating the algorithm for identifying suitable papers for inclusion. This comprehensive literature at last found 17 eligible studies that used miRNAs as biomarkers for gastric cancer diagnosis by method of qRT-PCR.

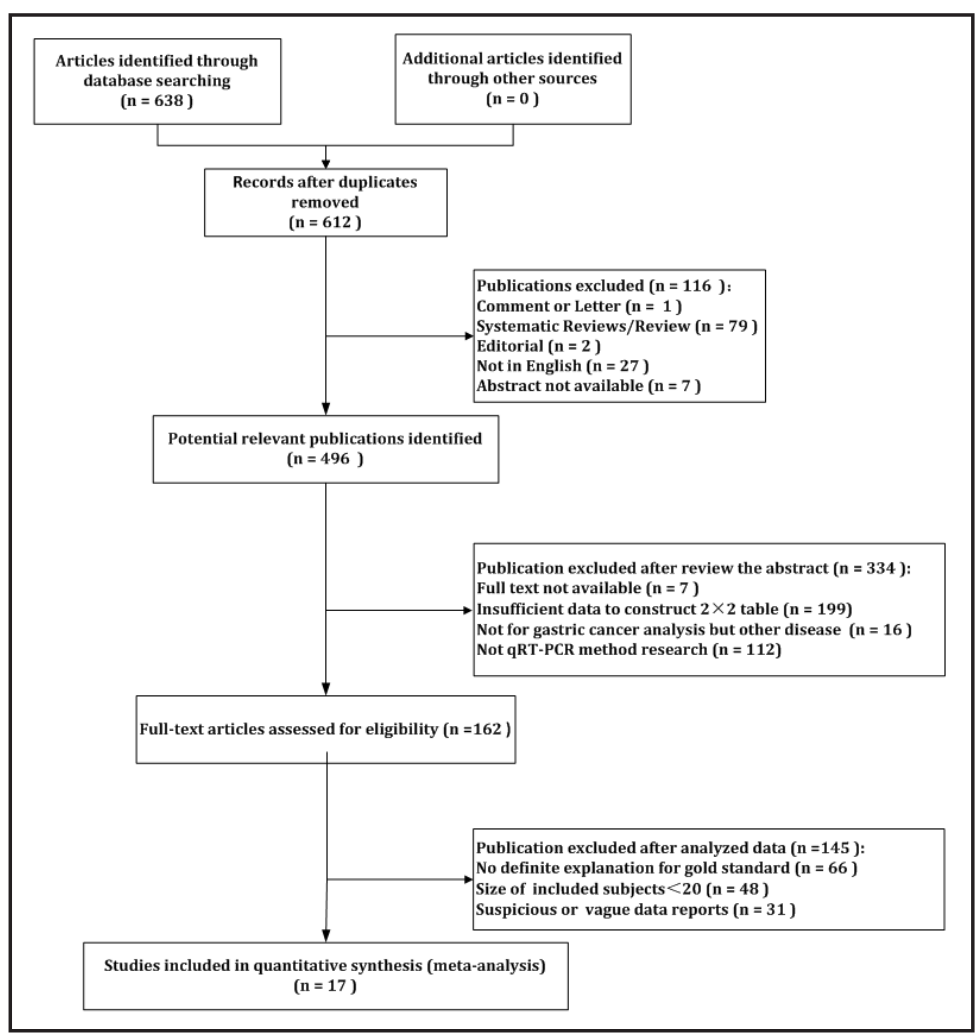

Meta-analysis

We utilized the meta-disc software version 1.4 to analyze the data. We generated forest plots as Figure 2 and demonstrated that the pooled sensitivity was 0.77 (95\%CI: 0.75-0.79; $\mathrm{Q}=143.42, \mathrm{p}=0.000, \mathrm{I}^{2} \%=81.2 \%$ ) and the specificity was 0.78 (95\%CI: 0.76-0.80; $\mathrm{Q}=179.97$, $\mathrm{P}=0.000, \mathrm{I}^{2} \%=85.0 \%$ ), indicating a significant heterogeneity among these studies. We then used random-effects models to re-analyze the data and analyzed the diagnostic threshold. The spearman correlation coefficient was $0.166(\mathrm{p}=0.398)$, indicating that the heterogeneity was not caused by diagnostic threshold. Next, we generated forest plots of DOR. The DOR of each study did not display a straight line distribution and the Cochran-Q value was $77.51(\mathrm{P}=0.000)$, indicating substantial heterogeneity. This may be caused by discrepancy of studied population, specimen type, endogenous reference, or total sample size. Metaregression analysis (data not shown) on the probable factors suggested that specimen type was probably the cause for heterogeneity.

\section{Subgroup analysis}

Due to high heterogeneity, the data (such as sensitivity) could not be simply pooled, but was only suitable for subgroup analyses. Filtering studies based on specimen type reduced heterogeneity to acceptable levels; for example, on sROC curve, the maximum joint sensitivity and specificity (Q value) was 0.7832 and the AUC was 0.8521 , indicating a high level of overall accuracy. In a group of five studies, which included seven panels of miRNAs from serum, the pooled sensitivity was 0.79 (95\%CI: $\left.0.75-0.83 ; \mathrm{I}^{2} \%=44.6 \%\right)$, and the pooled specificity was 0.71 (95\%CI: 0.67-0.76; $\mathrm{I}^{2} \%=86.2 \%$ ). However, in the 2 studies that included 4 miRNAs from peripheral blood, the pooled sensitivity, specificity, LR+, LR-, and DOR were 0.58 (95\%CI: 0.50-0.65; I I \%=22.2\%), 0.90 (95\%CI: 0.82-0.95; I²\%=42.1\%), 4.52 (95\%CI: 2.52-8.09; I²\%=0\%), 0.48 (95\%CI: 0.39-0.59; I²\%=21.0\%), and 9.85 (95\%CI: 4.70-20.66; $\mathrm{I}^{2} \%=0 \%$ ), respectively. In the subgroup of studies using plasma samples, the heterogeneity was high; thus, a pooled study was not appropriate. The pooled sensitivity, specificity, LR+, LR- and DOR in plasma vs. gastric juice are 0.85 vs. $0.65,0.78$ vs. $0.81,4.51$ vs. $3.42,0.20$ vs. 0.41 , and 28.8 vs. 18.80 , respectively. 
A

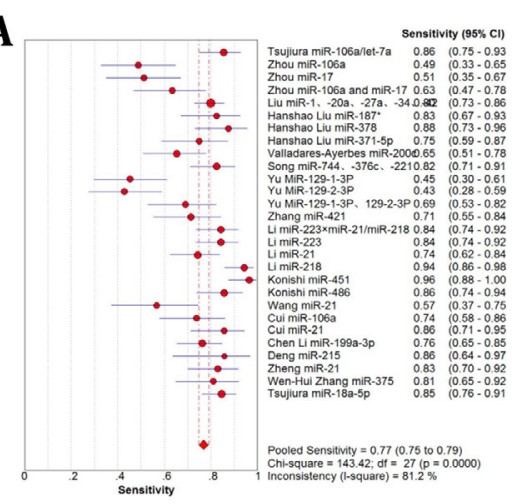

C

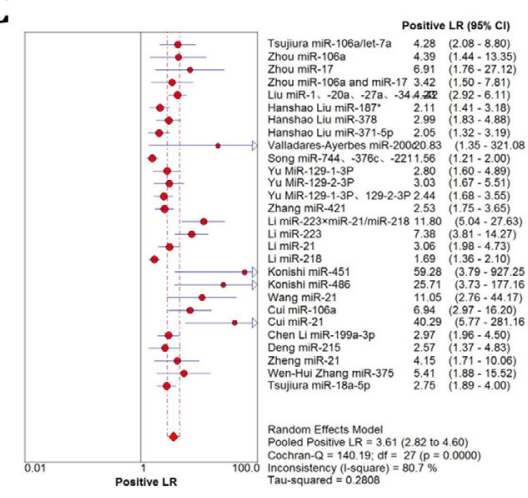

$\mathbf{E}$

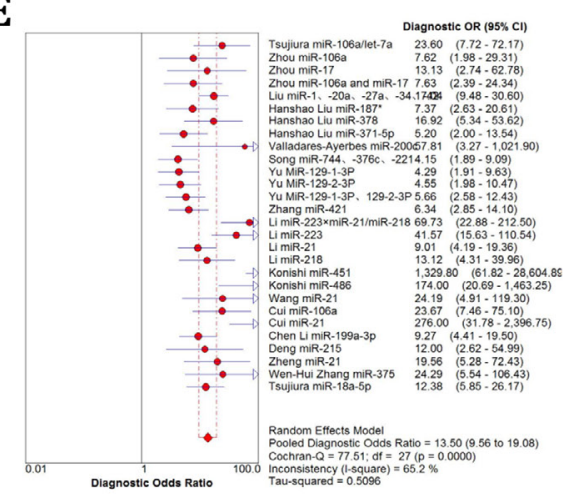

B

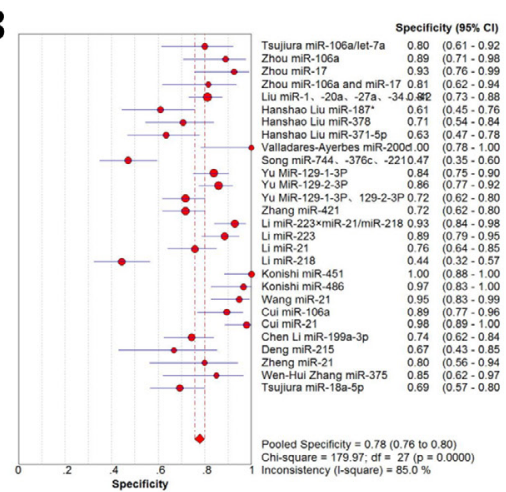

D

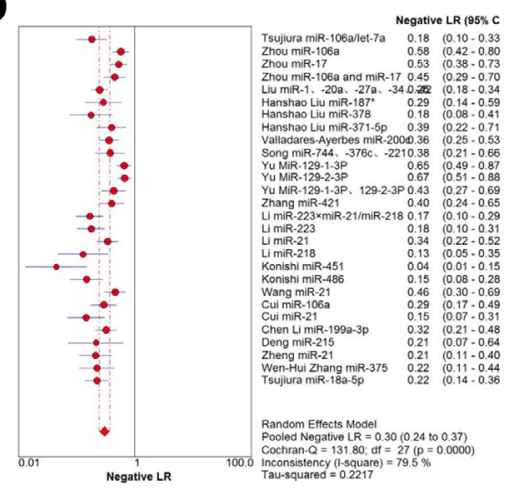

$\mathbf{F}$

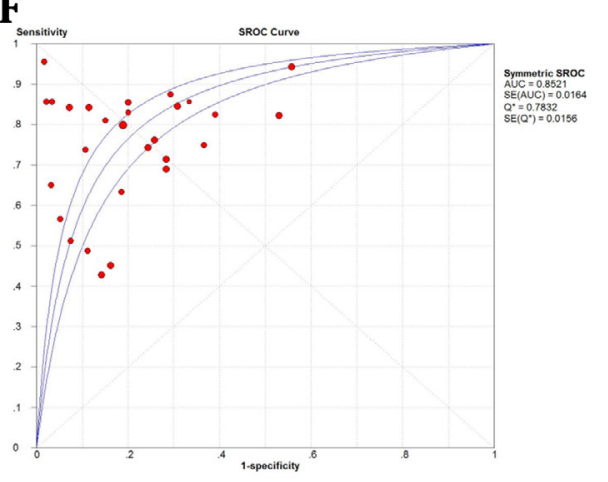

Fig. 2. Forest plot of diagnostic value index of altered miRNA expression in gastric cancer. A, Sensitivity of altered miRNA expression in diagnosis of gastric cancer in all studies. B, Specificity of altered miRNA expression in diagnosis of gastric cancer in all studies. C, Positive likelihood ratio of altered miRNA expression in diagnosis of gastric cancer in all studies. D, Negative likelihood ratio of altered miRNA expression in diagnosis of gastric cancer in all studies. E, Diagnostic odds ratio of altered miRNA expression in diagnosis of gastric cancer in all studies. E, sROC of altered miRNA expression in diagnosis of gastric cancer in all studies.

Clinical studies that supplied the ratio of dysregulated miRNAs in gastric cancer tissues

Since obtaining normal tissue specimens is an invasive procedure, we were unable to retrieve a large number of studies using normal tissues to validate the diagnostic value of altered miRNAs. However, tissues adjacent or distant to tumor lesions is easier to acquire and more reliable as it eliminates inter-individual discrepancies. We identified 34 multi- 


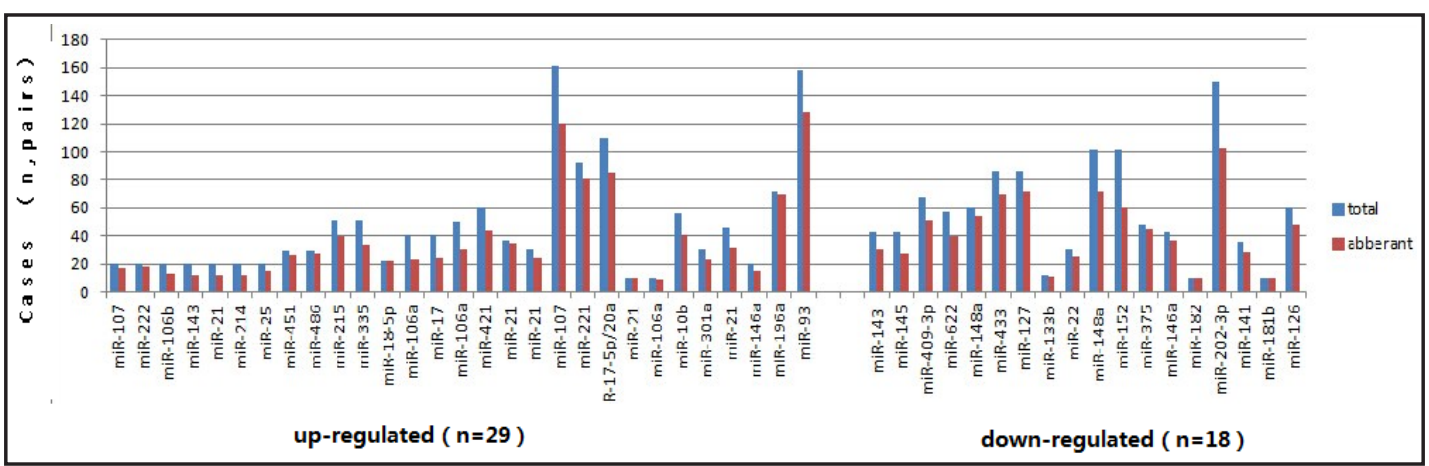

Fig. 3. Illustration of dysregulated miRNA ratio in gastric cancer tissues. The ordinate is the number of cases in each included study; The abscissa shows the 29 up-regulated miRNAs before the blank and 18 down-regulated miRNAs after the blank.

Table 3. Altered expression of miRNAs associated with clinicopathological features from gastric cancer patients

\begin{tabular}{|c|c|}
\hline $\begin{array}{l}\text { Clinicopathological } \\
\text { factors }\end{array}$ & Altered expression of miRNAs \\
\hline Survive time & miR-21[40], miR-146a[36], miR-10b[17], miR-93[41] \\
\hline Tumor size & $\begin{array}{l}\text { miR-148/152 [42], miR-126[43], miR-200c[44], miR-106a[37], miR-17-5p/20a[45], miR- } \\
\text { 10b[17], miR-93[41], miR-21[32], miR-409-3p, miR-202-3p[46] }\end{array}$ \\
\hline MiRNA-target gene & $\begin{array}{l}\text { miR-126-Crk[43], miR-21-PTEN[47]/ miR-106a-FAS[37], miR-17-5p/20a- } \\
\text { TP53INP1/MDM2[45], miR-22-Sp1[48], miR-622-ING1[49], miR-146a-SMAD4[50], miR- } \\
\text { 202-3p- Gli1[46], miR-181a-5p- BCL2/K-RAS/GATA6/ CDX2[14], miR-433-MAPK4[51], } \\
\text { miR-127-KRAS [51], miR-148a-SMAD2[52] }\end{array}$ \\
\hline Cell differentiation & miR-146a[36], miR-21[47], miR-10b[17], miR-622 [49], miR-181a-5p[14], miR-148a[52] \\
\hline TMN staging & $\begin{array}{l}\text { miR-378[53], miR-421[34], miR-223 and miR-21/miR-218[33], miR-451[21], miR-107[54], } \\
\text { miR-547-3p[20], miR-10b[17], miR-93[41], miR-21[32], miR-215[28], miR-433 [51], miR- } \\
\text { 148a[52] }\end{array}$ \\
\hline Lymphatic metastasis & $\begin{array}{l}\text { miR-200c[44], miR-21[47], miR-451[21], miR-107[54], miR-221[55], miR-10b[17], miR- } \\
\text { 93[41], miR-622[49] }\end{array}$ \\
\hline Sex & miR-129-1-3P[56] \\
\hline Age & $\operatorname{miR}-202-3 p[46]$ \\
\hline Tumor invasion & $\begin{array}{l}\text { miR-21[47], miR-107[54], miR-106a[37], miR-221[55], miR-10b[17] , miR-215[28], miR- } \\
93[41], \text { miR-181a-5p[14] }\end{array}$ \\
\hline Pathological type & $\operatorname{miR}-21[57], \operatorname{miR}-93[41], \operatorname{miR}-21[32]$ \\
\hline Radio/chemotherapy & miR-143 and miR-145 increase 5-FU sensitivity [58] \\
\hline
\end{tabular}

center, cohort studies from 4 countries that provided data on altered expression of miRNAs. Specifically, two studies [21,31] utilized plasma from pre- and post-operative gastric cancer patients, while one study [35] used peripheral blood, two studies [36, 37] used FFPE tissues, and two studies from the same laboratory $[38,39]$ assessed down-regulated miR-181b and miR-182 in 10 gastric adenocarcinoma tissues. Furthermore, only a few studies performed subgroup data analyses for association with clinicopathological features and the miRNAs studied were different in each of these studies. The altered miRNA expression and its frequency are shown in Figure 3. Respectively, there are 29 up-regulated miRNAs (including 
miR-107, miR-222, and miR-106b and 18 down-regulated miRNAs (including miR-143, miR145, miR622 and miR148a) in gastric cancer tissues vs. controls. The mean ratio of these dysregulated miRNAs was 0.766 .

Association of differentially expressed miRNAs with clinicopathological factors

Association of differentially expressed miRNAs with clinicopathological factors from gastric cancer patients was shown in Table 3. Differential expression of miRNAs was associated with age, gender, tumor size, TMN stage, tumor differentiation, lymphatic metastasis, tumor invasion, pathological type, response to radiotherapy and chemotherapy, and prognosis. These differentially expressed miRNAs were also associated with altered expression of some of their target genes.

\section{Discussion}

In this study, we retrieved and analyzed published studies on altered miRNA expression in gastric cancer. Our data showed aberrantly expressed miRNAs in gastric cancer, with 25 upregulated and 14 down-regulated miRNAs being the most frequently altered. Among them, the miR-17-92 cluster was generally up-regulated in gastric cancer tissues. Our data analysis also showed that specific miRNAs could be used (with moderate sensitivity and specificity, and a high level of the overall accuracy) in the diagnosis of gastric cancer. However, it is to be noted that there was substantial heterogeneity in the data most likely attributable to the specimen types. Furthermore, we found that the mean ratio of dysregulated miRNAs in a large number of clinical studies was 0.766 . The published studies also showed association of altered miRNA expression with clinicopathological data from gastric cancer patients. Thus, future studies are required to further validate these differentially expressed miRNAs in gastric cancer as biomarkers for early diagnosis of gastric cancer, prognosis and prediction of treatment responses.

To date, there are a number of available biomarkers, such as CEA, CA199, and CA724 for diagnosis of gastric cancer, but their sensitivity and specificity are low [6]. So we necessarily need a novel effective biomarker for diagnosing gastric cancer at early stages. Detection of altered expression of miRNAs could have several advantages [59-61], i.e., i). miRNAs are usually stable in fresh tissues, FFPE tissue, cells and peripheral blood [31, 62-66] because they are short and resistant to degradation; ii). Each miRNA is specifically expressed in tissue specimens [67]; iii). miRNAs have been shown to be differentially expressed in gastric cancer vs. normal tissues; and iv). Altered miRNA expression has been shown to contribute to tumorigenesis and cancer progression; v). Association of miRNA expression with tumor stages has been demonstrated $[68,69]$. Thus, research on miRNA could help us to develop novel biomarkers and to better understand the molecular mechanism of gastric cancer development.

Indeed, our current study showed 25 most frequently upregulated and 14 downregulated miRNAs in gastric cancer. Future studies with a larger sample size are needed to confirm these data. Furthermore, different miRNAs have different target genes and thus, future studies should also analyze expression of their target genes for generating combined biomarkers to be used for the early detection of gastric cancer or prediction of survival and treatment responses. Finally, the specificity of these miRNA biomarkers should be further confirmed by comparing samples from the patients with gastric cancers and the patients with other type of cancers.

Furthermore, the functional analysis of miRNAs might be also important for the choice of diagnostic miRNAs. For example, miR-451 has been linked to controlling expression of p-glycprotein, a critical protein controls multidrug resistance in cancer cells [70]. And miR106 family (miR-106b, miR-93 and miR-25) overexpresses in gastric cancer stem cells [71]. Thus, the physicians should take the functions of these miRNAs into consideration when they look for good candidates for gastric cancer biomarkers. 
However, our current study does have some limitations; for example, there are always unique data from published studies, but not unified set of data for meta analysis. The biological functions of blood miRNAs are not clear, making data interpretation difficult. Moreover, the drawback of these retrieved studies is that consideration was not given for gastric cancer risk factors, such as Helicobacter pylori infection, genetics, diet and other risk factors that may contribute to altered expression of miRNAs. Infection of Helicobacter pylori is an important factor in gastric cancer development and the expression of different miRNAs were shown to be significantly associated with infection of Helicobacter pylori [72]. In addition, each study has its own study design, use of miRNA chips, endogenous reference, pathology type, and localization of gastric cancer lesions, which makes the analysis difficult.

\section{Financial Disclosure}

This study was supported in part by a grant from The Natural Science Foundation of Hubei Province (\#2012FFB04303). The funders had no role in study design, data collection and analysis, decision to publish, or preparation of the manuscript.

\section{Disclosure Statement}

The authors have declared that no competing interests exist.

\section{References}

1 Jemal A, Bray F, Center MM, Ferlay J, Ward E, Forman D: Global cancer statistics. CA Cancer J Clin 2011;61:69-90.

2 Kitano S, Shiraishi N, Uyama I, Sugihara K, Tanigawa N: A multicenter study on oncologic outcome of laparoscopic gastrectomy for early cancer in Japan. Ann Surg 2007;245:68-72.

-3 Uedo N, Takeuchi Y, Ishihara R: Endoscopic management of early gastric cancer: Endoscopic mucosal resection or endoscopic submucosal dissection: Data from a Japanese high-volume center and literature review. Ann Gastroenterol 2012;25:281-290.

- Kaneko S, Yoshimura T: Time trend analysis of gastric cancer incidence in Japan by histological types, 1975-1989. Br J Cancer 2001;84:400-405.

-5 Bonenkamp JJ, Hermans J, Sasako M, van de Velde CJ, Welvaart K, Songun I, Meyer S, Plukker JT, Van Elk P, Obertop H, Gouma DJ, van Lanschot JJ, Taat CW, de Graaf PW, von Meyenfeldt MF, Tilanus H: Extended lymph-node dissection for gastric cancer. N Engl J Med 1999;340:908-914.

6 Liu X, Cai H, Wang Y: Prognostic significance of tumour markers in Chinese patients with gastric cancer. Anz J Surg 10.1111/j.1445-2197.2012.06287.x

7 Chen CZ: MicroRNAs as oncogenes and tumor suppressors. N Engl J Med 2005;353:1768-1771.

8 Lee RC, Feinbaum RL, Ambros V: The C. Elegans heterochronic gene lin-4 encodes small RNAs with antisense complementarity to lin-14. Cell 1993;75:843-854.

-9 Carthew RW, Sontheimer EJ: Origins and mechanisms of miRNAs and siRNAs. Cell 2009;136:642-655.

10 Gorur A, Balci FS, Dogruer UN, Ayaz L, Akbayir S, Yildirim YH, Dirlik M, Serin MS, Tamer L: Determination of plasma microRNA for early detection of gastric cancer. Mol Biol Rep 2013;40:2091-2096.

11 Liu H, Zhu L, Liu B, Yang L, Meng X, Zhang W, Ma Y, Xiao H: Genome-wide microRNA profiles identify miR378 as a serum biomarker for early detection of gastric cancer. Cancer Lett 2012;316:196-203.

-12 Tchernitsa O, Kasajima A, Schafer R, Kuban RJ, Ungethum U, Gyorffy B, Neumann U, Simon E, Weichert W, Ebert MP, Rocken C: Systematic evaluation of the miRNA-ome and its downstream effects on mRNA expression identifies gastric cancer progression. J Pathol 2010;222:310-319.

13 Chen Z, Saad R, Jia P, Peng D, Zhu S, Washington MK, Zhao Z, Xu Z, El-Rifai W: Gastric adenocarcinoma has a unique microRNA signature not present in esophageal adenocarcinoma. Cancer 2013;119:1985-1993. 
14 Chen G, Shen ZL, Wang L, Lv CY, Huang XE, Zhou RP: Hsa-miR-181a-5p expression and effects on cell proliferation in gastric cancer. Asian Pac J Cancer Prev 2013;14:3871-3875.

- 15 Yao Y, Suo AL, Li ZF, Liu LY, Tian T, Ni L, Zhang WG, Nan KJ, Song TS, Huang C: MicroRNA profiling of human gastric cancer. Mol Med Rep 2009;2:963-970.

-16 Li X, Luo F, Li Q, Xu M, Feng D, Zhang G, Wu W: Identification of new aberrantly expressed miRNAs in intestinal-type gastric cancer and its clinical significance. Oncol Rep 2011;26:1431-1439.

17 Wang YY, Ye ZY, Zhao ZS, Li L, Wang YX, Tao HQ, Wang HJ, He XJ: Clinicopathologic significance of miR-10b expression in gastric carcinoma. Hum Pathol 2013;44:1278-1285.

- 18 Zhang WH, Gui JH, Wang CZ, Chang Q, Xu SP, Cai CH, Li YN, Tian YP, Yan L, Wu B: The identification of miR375 as a potential biomarker in distal gastric adenocarcinoma. Oncol Res 2012;20:139-147.

19 Tsukamoto Y, Nakada C, Noguchi T, Tanigawa M, Nguyen LT, Uchida T, Hijiya N, Matsuura K, Fujioka T, Seto M, Moriyama M: MicroRNA-375 is downregulated in gastric carcinomas and regulates cell survival by targeting PDK1 and 14-3-3zeta. Cancer Res 2010;70:2339-2349.

20 Su Y, Ni Z, Wang G, Cui J, Wei C, Wang J, Yang Q, Xu Y, Li F: Aberrant expression of microRNAs in gastric cancer and biological significance of miR-574-3p. Int Immunopharmacol 2012;13:468-475.

21 Konishi H, Ichikawa D, Komatsu S, Shiozaki A, Tsujiura M, Takeshita H, Morimura R, Nagata H, Arita T, Kawaguchi T, Hirashima S, Fujiwara H, Okamoto K, Otsuji E: Detection of gastric cancer-associated microRNAs on microRNA microarray comparing pre- and post-operative plasma. Br J Cancer 2012;106:740-747.

22 Guo J, Miao Y, Xiao B, Huan R, Jiang Z, Meng D, Wang Y: Differential expression of microRNA species in human gastric cancer versus non-tumorous tissues. J Gastroenterol Hepatol 2009;24:652-657.

-23 Ding L, Xu Y, Zhang W, Deng Y, Si M, Du Y, Yao H, Liu X, Ke Y, Si J, Zhou T: MiR-375 frequently downregulated in gastric cancer inhibits cell proliferation by targeting JAK2. Cell Res 2010;20:784-793.

24 Katada T, Ishiguro H, Kuwabara Y, Kimura M, Mitui A, Mori Y, Ogawa R, Harata K, Fujii Y: MicroRNA expression profile in undifferentiated gastric cancer. Int J Oncol 2009;34:537-542.

25 Li X, Zhang Y, Zhang H, Liu X, Gong T, Li M, Sun L, Ji G, Shi Y, Han Z, Han S, Nie Y, Chen X, Zhao Q, Ding J, Wu K, Daiming F: MiRNA-223 promotes gastric cancer invasion and metastasis by targeting tumor suppressor EPB41L3. Mol Cancer Res 2011;9:824-833.

-26 Ueda T, Volinia S, Okumura H, Shimizu M, Taccioli C, Rossi S, Alder H, Liu CG, Oue N, Yasui W, Yoshida K, Sasaki H, Nomura S, Seto Y, Kaminishi M, Calin GA, Croce CM: Relation between microRNA expression and progression and prognosis of gastric cancer: A microRNA expression analysis. Lancet Oncol 2010;11:136146.

27 Carvalho J, van Grieken NC, Pereira PM, Sousa S, Tijssen M, Buffart TE, Diosdado B, Grabsch H, Santos MA, Meijer G, Seruca R, Carvalho B, Oliveira C: Lack of microRNA-101 causes E-cadherin functional deregulation through EZH2 up-regulation in intestinal gastric cancer. J Pathol 2012;228:31-44.

28 Deng Y, Huang Z, Xu Y, Jin J, Zhuo W, Zhang C, Zhang X, Shen M, Yan X, Wang L, Wang X, Kang Y, Si J, Zhou T: MiR-215 modulates gastric cancer cell proliferation by targeting RB1. Cancer Lett 2014;342:27-35.

29 Tsujiura M, Ichikawa D, Komatsu S, Shiozaki A, Takeshita H, Kosuga T, Konishi H, Morimura R, Deguchi K, Fujiwara H, Okamoto K, Otsuji E: Circulating microRNAs in plasma of patients with gastric cancers. Br J Cancer 2010;102:1174-1179.

-30 Li C, Li JF, Cai Q, Qiu QQ, Yan M, Liu BY, Zhu ZG: MiRNA-199a-3p: A potential circulating diagnostic biomarker for early gastric cancer. J Surg Oncol 2013;108:89-92.

-31 Tsujiura M, Komatsu S, Ichikawa D, Shiozaki A, Konishi H, Takeshita H, Moriumura R, Nagata H, Kawaguchi T, Hirajima S, Arita T, Fujiwara H, Okamoto K, Otsuji E: Circulating miR-18a in plasma contributes to cancer detection and monitoring in patients with gastric cancer. Gastric Cancer 2014

- 32 Zheng Y, Cui L, Sun W, Zhou H, Yuan X, Huo M, Chen J, Lou Y, Guo J: MicroRNA-21 is a new marker of circulating tumor cells in gastric cancer patients. Cancer Biomark 2011;10:71-77.

-33 Li BS, Zhao YL, Guo G, Li W, Zhu ED, Luo X, Mao XH, Zou QM, Yu PW, Zuo QF, Li N, Tang B, Liu KY, Xiao B: Plasma microRNAs, miR-223, miR-21 and miR-218, as novel potential biomarkers for gastric cancer detection. PLoS One 2012; 7:e41629.

34 Zhang X, Cui L, Ye G, Zheng T, Song H, Xia T, Yu X, Xiao B, Le Y, Guo J: Gastric juice microRNA-421 is a new biomarker for screening gastric cancer. Tumour Biol 2012;33:2349-2355. 
Wang et al.: Altered MiRNA Expression in Gastric Cancer

35 Zhou H, Guo JM, Lou YR, Zhang XJ, Zhong FD, Jiang Z, Cheng J, Xiao BX: Detection of circulating tumor cells in peripheral blood from patients with gastric cancer using microRNA as a marker. J Mol Med (Berl) 2010;88:709-717.

-36 Hou Z, Yin H, Chen C, Dai X, Li X, Liu B, Fang X: MicroRNA-146a targets the L1 cell adhesion molecule and suppresses the metastatic potential of gastric cancer. Mol Med Rep 2012;6:501-506.

37 Wang Z, Liu M, Zhu H, Zhang W, He S, Hu C, Quan L, Bai J, Xu N: MiR-106a is frequently upregulated in gastric cancer and inhibits the extrinsic apoptotic pathway by targeting FAS. Mol Carcinog 2013;52:634646.

-38 Kong WQ Bai R, Liu T, Cai CL, Liu M, Li X, Tang H: MicroRNA-182 targets cAMP-responsive element-binding protein 1 and suppresses cell growth in human gastric adenocarcinoma. FEBS J 2012;279:1252-1260.

39 Chen L, Yang Q, Kong WQ, Liu T, Liu M, Li X, Tang H: MicroRNA-181b targets cAMP responsive element binding protein 1 in gastric adenocarcinomas. Iubmb Life 2012;64:628-635.

40 Chan SH, Wu CW, Li AF, Chi CW, Lin WC: MiR-21 microRNA expression in human gastric carcinomas and its clinical association. Anticancer Res 2008;28:907-911.

41 Chen L, Jiang M, Yuan W, Tang H: Prognostic value of miR-93 overexpression in resectable gastric adenocarcinomas. Acta Gastroenterol Belg 2012;75:22-27.

42 Chen Y, Song Y, Wang Z, Yue Z, Xu H, Xing C, Liu Z: Altered expression of MiR-148a and MiR-152 in gastrointestinal cancers and its clinical significance. J Gastrointest Surg 2010;14:1170-1179.

43 Feng R, Chen X, Yu Y, Su L, Yu B, Li J, Cai Q, Yan M, Liu B, Zhu Z: MiR-126 functions as a tumour suppressor in human gastric cancer. Cancer Lett 2010;298:50-63.

-44 Valladares-Ayerbes M, Reboredo M, Medina-Villaamil V, Iglesias-Diaz P, Lorenzo-Patino MJ, Haz M, Santamarina I, Blanco M, Fernandez-Tajes J, Quindos M, Carral A, Figueroa A, Anton-Aparicio LM, Calvo L: Circulating miR-200c as a diagnostic and prognostic biomarker for gastric cancer. J Transl Med 2012;10:186.

-45 Wang M, Gu H, Qian H, Zhu W, Zhao C, Zhang X, Tao Y, Zhang L, Xu W: MiR-17-5p/20a are important markers for gastric cancer and murine double minute 2 participates in their functional regulation. Eur J Cancer 2013;49:2010-2021.

-46 Zhao Y, Li C, Wang M, Su L, Qu Y, Li J, Yu B, Yan M, Yu Y, Liu B, Zhu Z: Decrease of miR-202-3p expression, a novel tumor suppressor, in gastric cancer. PLoS One 2013;8:e69756.

47 Zhang BG, Li JF, Yu BQ Zhu ZG, Liu BY, Yan M: MicroRNA-21 promotes tumor proliferation and invasion in gastric cancer by targeting PTEN. Oncol Rep 2012;27:1019-1026.

-48 Guo MM, Hu LH, Wang YQ Chen P, Huang JG, Lu N, He JH, Liao CG: MiR-22 is down-regulated in gastric cancer, and its overexpression inhibits cell migration and invasion via targeting transcription factor Sp1. Med Oncol 2013;30:542.

49 Guo XB, Jing CQ, Li LP, Zhang L, Shi YL, Wang JS, Liu JL, Li CS: Down-regulation of miR-622 in gastric cancer promotes cellular invasion and tumor metastasis by targeting ING1 gene. World J Gastroenterol 2011;17:1895-1902.

-50 Xiao B, Zhu ED, Li N, Lu DS, Li W, Li BS, Zhao YL, Mao XH, Guo G, Yu PW, Zou QM: Increased miR-146a in gastric cancer directly targets SMAD4 and is involved in modulating cell proliferation and apoptosis. Oncol Rep 2012;27:559-566.

51 Guo LH, Li H, Wang F, Yu J, He JS: The tumor suppressor roles of miR-433 and miR-127 in gastric cancer. Int J Mol Sci 2013;14:14171-14184.

-52 Wang SH, Li X, Zhou LS, Cao ZW, Shi C, Zhou CZ, Wen YG, Shen Y, Li JK: MicroRNA-148a suppresses human gastric cancer cell metastasis by reversing epithelial-to-mesenchymal transition. Tumour Biol 2013;34:3705-3712.

53 Liu H, Zhu L, Liu B, Yang L, Meng X, Zhang W, Ma Y, Xiao H: Genome-wide microRNA profiles identify miR378 as a serum biomarker for early detection of gastric cancer. Cancer Lett 2012;316:196-203.

-54 Inoue T, Iinuma H, Ogawa E, Inaba T, Fukushima R: Clinicopathological and prognostic significance of microRNA-107 and its relationship to DICER1 mRNA expression in gastric cancer. Oncol Rep 2012;27:1759-1764.

55 Liu K, Li G, Fan C, Diao Y, Wu B, Li J: Increased Expression of MicroRNA-221 in gastric cancer and its clinical significance. J Int Med Res 2012;40:467-474.

56 Yu X, Luo L, Wu Y, Yu X, Liu Y, Yu X, Zhao X, Zhang X, Cui L, Ye G, Le Y, Guo J: Gastric juice miR-129 as a potential biomarker for screening gastric cancer. Med Oncol 2013;30:365. 
Wang et al.: Altered MiRNA Expression in Gastric Cancer

57 Cui L, Zhang X, Ye G, Zheng T, Song H, Deng H, Xiao B, Xia T, Yu X, Le Y, Guo J: Gastric juice MicroRNAs as potential biomarkers for the screening of gastric cancer. Cancer 2013;119:1618-1626.

58 Takagi T, Iio A, Nakagawa Y, Naoe T, Tanigawa N, Akao Y: Decreased expression of microRNA-143 and -145 in human gastric cancers. Oncology-Basel 2009;77:12-21.

59 Pignot G, Cizeron-Clairac G, Vacher S, Susini A, Tozlu S, Vieillefond A, Zerbib M, Lidereau R, Debre B, Amsellem-Ouazana D, Bieche I: MicroRNA expression profile in a large series of bladder tumors: Identification of a 3-miRNA signature associated with aggressiveness of muscle-invasive bladder cancer. Int J Cancer 2013;132:2479-2491.

-60 Dettmer M, Vogetseder A, Durso MB, Moch H, Komminoth P, Perren A, Nikiforov YE, Nikiforova MN: MicroRNA expression array identifies novel diagnostic markers for conventional and oncocytic follicular thyroid carcinomas. J Clin Endocrinol Metab 2013;98:E1-E7.

61 Heneghan HM, Miller N, Kerin MJ: MiRNAs as biomarkers and therapeutic targets in cancer. Curr Opin Pharmacol 2010;10:543-550.

62 Chen X, Ba Y, Ma L, Cai X, Yin Y, Wang K, Guo J, Zhang Y, Chen J, Guo X, Li Q Li X, Wang W, Zhang Y, Wang J, Jiang X, Xiang Y, Xu C, Zheng P, Zhang J, Li R, Zhang H, Shang X, Gong T, Ning G, Wang J, Zen K, Zhang J, Zhang CY: Characterization of microRNAs in serum: A novel class of biomarkers for diagnosis of cancer and other diseases. Cell Res 2008;18:997-1006.

63 Taylor DD, Gercel-Taylor C: MicroRNA signatures of tumor-derived exosomes as diagnostic biomarkers of ovarian cancer. Gynecol Oncol 2008;110:13-21.

64 Mitchell PS, Parkin RK, Kroh EM, Fritz BR, Wyman SK, Pogosova-Agadjanyan EL, Peterson A, Noteboom J, O'Briant KC, Allen A, Lin DW, Urban N, Drescher CW, Knudsen BS, Stirewalt DL, Gentleman R, Vessella RL, Nelson PS, Martin DB, Tewari M: Circulating microRNAs as stable blood-based markers for cancer detection. Proc Natl Acad Sci U S A 2008;105:10513-10518.

-65 Gilad S, Meiri E, Yogev Y, Benjamin S, Lebanony D, Yerushalmi N, Benjamin H, Kushnir M, Cholakh H, Melamed N, Bentwich Z, Hod M, Goren Y, Chajut A: Serum microRNAs are promising novel biomarkers. PLoS One 2008;3:e3148.

66 Ho AS, Huang X, Cao H, Christman-Skieller C, Bennewith K, Le QT, Koong AC: Circulating miR-210 as a novel hypoxia marker in pancreatic cancer. Transl Oncol 2010;3:109-113.

67 Rosenfeld N, Aharonov R, Meiri E, Rosenwald S, Spector Y, Zepeniuk M, Benjamin H, Shabes N, Tabak S, Levy A, Lebanony D, Goren Y, Silberschein E, Targan N, Ben-Ari A, Gilad S, Sion-Vardy N, Tobar A, Feinmesser M, Kharenko O, Nativ O, Nass D, Perelman M, Yosepovich A, Shalmon B, Polak-Charcon S, Fridman E, Avniel A, Bentwich I, Bentwich Z, Cohen D, Chajut A, Barshack I: MicroRNAs accurately identify cancer tissue origin. Nat Biotechnol 2008;26:462-469.

68 Malumbres R, Sarosiek KA, Cubedo E, Ruiz JW, Jiang X, Gascoyne RD, Tibshirani R, Lossos IS: Differentiation stage-specific expression of microRNAs in B lymphocytes and diffuse large B-cell lymphomas. Blood 2009;113:3754-3764.

69 Yan LX, Huang XF, Shao Q Huang MY, Deng L, Wu QL, Zeng YX, Shao JY: MicroRNA miR-21 overexpression in human breast cancer is associated with advanced clinical stage, lymph node metastasis and patient poor prognosis. Rna 2008;14:2348-2360.

70 Zhu H, Wu H, Liu X, Evans BR, Medina DJ, Liu CG, Yang JM: Role of MicroRNA miR-27a and miR-451 in the regulation of MDR1/P-glycoprotein expression in human cancer cells. Biochem Pharmacol 2008;76:582588.

71 Yu D, Shin HS, Lee YS, Lee YC: MiR-106b modulates cancer stem cell characteristics through TGF-beta/ Smad signaling in CD44-positive gastric cancer cells. Lab Invest 2014;94:1370-1381.

72 Matsushima K, Isomoto H, Inoue N, Nakayama T, Hayashi T, Nakayama M, Nakao K, Hirayama T, Kohno S: MicroRNA signatures in Helicobacter pylori-infected gastric mucosa. Int J Cancer 2011;128:361-370. 